\title{
Noradrenergic Inhibition of Canine Gallbladder Contraction and Murine Pancreatic Secretion during Stress by Corticotropin-releasing Factor
}

\author{
H. Jürgen Lenz, ${ }^{\star \star}$ Bernhard Messmer, ${ }^{*}$ and Frank G. Zimmerman \\ *Division of Gastroenterology, Department of Medicine, University of California at San Diego, School of Medicine, La Jolla, California \\ 92093-0671; and ${ }^{\ddagger}$ Neurogastroenterology Laboratory, Department of Medicine, University of Hamburg, \\ 2000 Hamburg 20, Federal Republic of Germany
}

\begin{abstract}
Gastrointestinal secretory and motor responses are profoundly altered during stress; but the effects of stress and its mediator(s) on the two major gut functions, exocrine pancreatic secretion and gallbladder motility, are unknown. We therefore developed two animal models that allowed us to examine the effects of acoustic stress on canine gallbladder contraction and restraint stress on rat exocrine pancreatic secretion. Acoustic stress inhibited cholecystokinin-8 (CCK)- and meal-induced gallbladder contraction, and restraint stress inhibited basal and CCK/secretin-stimulated pancreatic secretion. These inhibitory responses were mimicked by cerebral injection of corticotropin-releasing factor (CRF) and abolished by the CRF antagonist, $\alpha$-helical CRF-(9-41). The effects of stress and exogenous CRF were simulated by intravenous infusion of norepinephrine but prevented by ganglionic, noradrenergic, and $\alpha$-adrenergic but not $\beta$-adrenergic receptor blockade. Vagotomy, adrenalectomy, and-in rats-hypophysectomy did not alter the effects produced by stress and CRF. These results indicate that endogenous CRF released in response to different stressors in distinct species inhibits canine gallbladder contraction and murine exocrine pancreatic secretion via activation of sympathetic efferents. Release of norepinephrine appears to be the final common pathway producing inhibition of biliary and pancreatic digestive function during stress mediated by cerebral CRF. (J. Clin. Invest. 1992. 89:437-443.) Key words: gallbladder contraction - pancreatic secretion - stress - corticotropin-releasing factor • neuropeptide
\end{abstract}

\section{Introduction}

After ingestion of a meal under normal conditions, the various digestive processes such as secretion, gut motility, and absorption are rather independent from central nervous system control. They are coordinated by the enteric nervous system, gut hormones, and paracrine factors (1). During stress, however, brain regions (cerebral cortex, limbic system, and hypothalamus) influence the informational outflow from brain stem centers to the gut and thereby affect gastrointestinal functions (2). Stress-related postprandial syndromes like abdominal cramping and diarrhea may be secondary to abnormal gastric

Address reprint requests to H. Jürgen Lenz, University of California, San Diego, School of Medicine, La Jolla, CA 92093-0671.

Received for publication 15 January 1991 and in revised form 4 October 1991.

J. Clin. Invest.

(c) The American Society for Clinical Investigation, Inc.

0021-9738/92/02/0437/07 \$2.00

Volume 89, February 1992, 437-443 motor function and enhanced colonic motility (3-5). However, the effects of mental or physical stress on the two major digestive processes, gallbladder contraction and exocrine pancreatic secretion, are, to the best of our knowledge, completely unknown. This paucity of knowledge appears to be secondary to the lack of suitable experimental models. It is of interest that both the gallbladder and the exocrine pancreas are densely innervated by adrenergic efferents but their physiological functions are not well defined $(6,7)$. In the endocrine pancreas, noradrenergic input inhibits insulin and stimulates glucagon secretion, and neuroglucopenia produces selective activation of the sympathetic efferents to the pancreas (8-11).

The 41-residue hypothalamic peptide, corticotropin-releasing factor (CRF; reference 12), appears to be the major endogenous central nervous system transmitter that produces characteristic gastrointestinal stress responses: inhibition of gastric acid secretion and gastrointestinal transit $(3,4,13-17)$ and stimulation of gastroduodenal bicarbonate secretions and colonic motility $(3,4,16,18,19)$. The central nervous system effects of CRF and stress are mediated primarily by increased sympathetic tone and, in part, by parasympathetic withdrawal (13-20) or, in one instance, by activation of a functional pituitary-gut axis (18). However, the effects of CRF on biliary and pancreatic digestive processes are unknown. We therefore developed two animal models that allowed us to examine the effects of stress and exogenous CRF on canine gallbladder contraction and rat exocrine pancreatic secretions.

The results of these studies indicate that CRF, released endogenously in response to acoustic and restraint stress, inhibits gallbladder contraction and pancreatic secretion, respectively. Release of norepinephrine acting on $\alpha$-adrenergic receptors appears to be the final common pathway inhibiting biliary and pancreatic digestive function during stress mediated by endogenous CRF.

\section{Methods}

Animal preparations. Male Sprague-Dawley rats (250-300 g) and male beagle dogs (9-10 kg) were obtained from Wiga (Sülzfeld, FRG). Animals were fed a standard diet and housed in single quarters under temperature-, humidity-, and illumination-controlled conditions. After abdominal surgery, animals were fed a liquid diet (Altromin Sonderdiät, Hamburg, FRG) for up to $7 \mathrm{~d}$. Dogs were fitted with a third cerebral ventricular cannula and a gastric fistula as previously described $(15,21)$. Some dogs subsequently underwent truncal vagotomy and pyloroplasty or bilateral adrenalectomy $(15,21,22)$. Adrenalectomized animals received prednisone $(5 \mathrm{mg} / \mathrm{d}$ with meals; Apotheke, Universitätskrankenhaus-Eppendorf, Hamburg, FRG) and had free access to $0.075 \mathrm{M} \mathrm{NaCl}$. Completeness of vagotomy was verified by a

1. Abbreviations used in this paper: CCK, cholecystokinin 8; CRF, corticotropin-releasing factor. 
negative 2-deoxy-D-glucose test (15). Animals were allowed to recover for $\geq 3$ wk before the experiment. To obtain venous access, an 18 French plastic catheter was inserted into a front leg vein on the day of the experiment.

$4 \mathrm{~d}$ before the experiment, rats were fitted with cerebral right lateral ventricular cannulae, a gastric fistula, and a right jugular venous catheter (16-18). $2 \mathrm{~d}$ before the experiment, under general anesthesia (xylazine at $6 \mathrm{mg} / \mathrm{kg}$; Rompun, Bayer AG, Leverkusen, FRG and ketamine hydrochloride at $50 \mathrm{mg} / \mathrm{kg}$; Ketanest, Parke-Davis, Morris Plains, NJ), they were fitted with a pancreatic catheter. The proximal bile duct was ligated and connected with the duodenum by polyethylene tubing ( $0.36 \mathrm{~mm}$ i.d., $0.96 \mathrm{~mm}$ o.d.). The distal common bile-pancreatic duct was cannulated with a second polyethylene catheter that was routed subcutaneously to exit in the interscapular region of the animal's neck. For $2 \mathrm{~d}$ before the experiment, pancreatic juice drained into a small plastic sack that was emptied every $8 \mathrm{~h}$. Some animals were subjected to bilateral truncal vagotomy or adrenalectomy (17), and hypophysectomized animals were commercially obtained (Wiga). Completeness of vagotomy was verified by a negative 2-deoxy-D-glucose test (17) and completeness of adrenalectomy and hypophysectomy by macroscopic inspection. Adrenalectomized animals and hypophysectomized animals had free access to $0.15 \mathrm{M} \mathrm{NaCl}$.

Experimental design. After a $24-\mathrm{h}$ fast, dogs were studied in modified Pavlov-type slings. To facilitate accurate measurement of gallbladder diameters, the abdomen was shaved on the day before the experiment. Rat CRF, the CRF receptor antagonist, $\alpha$-helical CRF-(9-41) (23), or sterile water as the control (vehicle for peptides) was injected cerebroventricularly in $10-\mu$ l volumes and intravenously in $200-\mu \mathrm{l}$ volumes over $1 \mathrm{~min}$ as described $(15,21)$. Peptide doses were given on separate days and in random order. Peptides were obtained from Dr. J. E. Rivier (Salk Institute, La Jolla, CA). In most experiments, gallbladder contraction was induced by infusion of cholecystokinin-8 (CCK; $20 \mathrm{pmol} / \mathrm{kg}$ per $\mathrm{h}$ i.v.). In some experiments gallbladder contraction was induced by intragastric administration of a blenderized meal consisting of cooked ground beef, bread, and butter $(240 \mathrm{ml}, 14 \mathrm{~g}$ fat, $32 \mathrm{~g}$ protein, $12 \mathrm{~g}$ carbohydrate). To mimic a postprandial pancreatic secretory response, exocrine pancreatic secretion was stimulated by simultaneous infusion of CCK and secretin ( $10 \mathrm{pmol} / \mathrm{kg}$ per $\mathrm{h}$ each). CRF (or control) was administered at the time the CCK infusion was begun or at the time the meal was given. The CRF antagonist was administered 15 min before CRF. In stress experiments, dogs were fitted with headphones and exposed for $1 \mathrm{~h}$ to "pop" music $(70-80 \mathrm{~dB})$ that was prerecorded at different speeds $(17,33$, and $45 \mathrm{rpm}$ in random order, $1 \mathrm{~min}$ each). In control experiments, dogs were equipped with headphones but not exposed to the music.

To examine the neurohumoral pathways mediating the effects of CRF and stress, pharmacological approaches were utilized: ganglionic blockade with chlorisondamine (1 mg/kg i.v.; Ecolid, CIBA-Geigy, Basel, Switzerland); noradrenergic blockade with bretylium $(10 \mathrm{mg} / \mathrm{kg}$ per h, Bretylol; American Critical Care, American Hospital Supply, McGaw Park, IL); $\beta$-adrenergic blockade with propranolol $(2 \mathrm{mg} / \mathrm{kg}$ per h, Dociton; Rhein-Pharma, Arzneimittelwerk GmbH, Heidelberg, FRG); opiate receptor blockade with naloxone $(1 \mathrm{mg} / \mathrm{kg}$ i.v.; Sigma Chemie GmbH, Deisenhofen, FRG); $\alpha$-adrenergic receptor blockade with phentolamine $(0.1-10 \mu \mathrm{mol} / \mathrm{kg}$ per $\mathrm{h}$; Regitin, CIBA-Geigy $\mathrm{GmbH}$, Wehr, FRG). These agents were given $15 \mathrm{~min}$ before gallbladder contraction was induced. Norepinephrine $(100 \mathrm{nmol} / \mathrm{kg}$ per $\mathrm{h}, \mathrm{Ar}-$ terenol; Hoechst AG, Frankfurt, FRG) was administered at the same time gallbladder contraction was induced. Completeness of autonomic nervous system, noradrenergic, and opiate blockades has been validated previously $(15-18,21,22)$. In additional experiments, adrenocorticotropic hormone (ACTH) or $\beta$-endorphin ( $100 \mathrm{pmol} / \mathrm{kg}$ per h) was intravenously infused for $1 \mathrm{~h}$.

Rats were fasted for $24 \mathrm{~h}$ but had free access to water until the beginning of the experiment. Animals were placed in 15-liter buckets to which they were accustomed. The gastric cannula was opened, the gastric content inspected, and the pancreatic catheter connected to a 0.5 $\mathrm{ml}$ syringe that was attached to the rim of the bucket with adhesive tape. The animal was not studied if residual gastric content was found. Pancreatic juice was aspirated manually in freely moving rats and quantitated in 15-min intervals for $1 \mathrm{~h}$. In stress experiments, physical restraint, a previously validated stressor $(5,18)$, was used. Briefly, the animal's trunk was secured to a wooden plate for $1 \mathrm{~h}$ with three metal clamps. This restraint at room temperature results in characteristic neuroendocrine and autonomic stress responses $(5,18)$. Control (sterile water) or peptides were injected cerebroventricularly in 5- $\mu$ l volumes and intravenously in $50-\mu 1$ volumes as described $(5,17,18)$. CRF or control was injected at the zero time point, whereas $\alpha$-helical CRF-(941 ) was injected at the -15 -min time point. Peptide doses were administered in random order. At the end of the experiment, animals were killed by cervical dislocation; a clean empty stomach and correct cerebral cannula placement were also verified (17). To delineate the neurohumoral pathways mediating the effects of stress and of CRF on exocrine pancreatic secretion in rats, the same pharmacological approaches were used as described in the dog experiments. Dosages and time course of administration were likewise the same.

Biological measurements. Gallbladder size was measured by realtime ultrasonography using a 5-MHz transducer (Toshiba model SSA77A) in the upright position. The transducer was placed in the right upper abdominal quadrant, and the greatest length of the gallbladder was determined on an oscilloscope screen with standardized calipers. Rotating the transducer by $90^{\circ}$, we determined the greatest width (transverse diameter) and the greatest depth (anterior-posterior diameter). Gallbladder volume was calculated using the sum-of-cylinder method as described (24). This method has been shown previously not to overestimate gallbladder volume (24). To reduce the variability of gallbladder volumes, three measurements were taken at each time point (time point $\pm 2 \mathrm{~min}$ ) and averaged. Pancreatic volumes were estimated by weighing the collected 15 -min samples, assuming a density of 1.0. Bicarbonate was determined on an automated titration system (Radiometer, Copenhagen, Denmark) using a previously validated back-titration method for low bicarbonate concentrations (18). Protein was measured as described (25).

Plasma measurements. $2 \mathrm{ml}$ of venous blood was removed, collected in chilled tubes containing $100 \mu 10.5 \mathrm{M}$ EDTA (EGTA for catecholamines), and centrifuged at $3,000 \mathrm{~g}$ at $4^{\circ} \mathrm{C}$ for $10 \mathrm{~min}$; plasma was stored at $-20^{\circ} \mathrm{C}$. Plasma concentrations of cortisol, ACTH, and $\beta$-endorphin were determined in duplicate by radioimmunoassay (DRGInstruments $\mathrm{GmbH}$, Marburg, FRG) (18). Plasma concentrations of epinephrine and norepinephrine were measured by a single isotope radioenzymatic method $(5,17,21)$. $S$-[methyl- ${ }^{3}$ ]Adenosyl-L-methionine was purchased from New England Nuclear (Boston, MA). Plasma glucose concentrations were determined by the glucose-oxidase method (Beckman Instruments, Inc., Palo Alto, CA) $(5,21)$.

Statistical analysis. The data were subjected to analysis of variance and differences between treatment groups were determined by the Newman-Keuls multiple-range test (21). Results obtained from five animals were expressed as means \pm SEM, and they were considered significant if $P<0.05$.

\section{Results}

Effects of CRF and stress. Acoustic stress and CRF $(0.5 \mathrm{nmol} /$ $\mathrm{kg}$ given cerebroventricularly) significantly increased plasma concentrations of norepinephrine, epinephrine, glucose, cortisol, ACTH, and $\beta$-endorphin (Table I). Basal gallbladder volumes ranged between 12.5 and $13.5 \mathrm{~cm}^{3}$ (Fig. $1 \mathrm{~A}$ ), and basal pancreatic volume secretion ranged between 465 and $515 \mu \mathrm{l} / \mathrm{h}$ $($ Fig. $1 \mathrm{~B}$ ). In dogs, CCK alone reduced gallbladder volume to $3.5 \mathrm{~cm}^{3}$ at $45 \mathrm{~min}$. Increasing doses of cerebral CRF significantly reversed CCK-induced gallbladder contraction; at the highest dose of CRF $(0.5 \mathrm{nmol} / \mathrm{kg})$, gallbladder volumes were not significantly different compared with resting gallbladder volumes (time 0; Fig. 1 A). In rats, increasing doses of cerebral 
Table I. Neuroendocrine Effects of Acoustic Stress and CRF

\begin{tabular}{|c|c|c|c|c|c|c|}
\hline & \multicolumn{2}{|c|}{ Control } & \multicolumn{2}{|c|}{ Stress } & \multicolumn{2}{|c|}{ CRF } \\
\hline & $0 \mathrm{~min}$ & $20 \mathrm{~min}$ & $0 \min$ & $20 \mathrm{~min}$ & $0 \mathrm{~min}$ & $20 \mathrm{~min}$ \\
\hline Norepinephrine $(n M)$ & $1.17 \pm 0.21$ & $1.37 \pm 0.24$ & $1.00 \pm 0.21$ & $2.74 \pm 0.44$ & $1.10 \pm 0.18$ & $2.98 \pm 0.53$ \\
\hline Epinephrine $(n M)$ & $0.52 \pm 0.11$ & $0.59 \pm 0.17$ & $0.61 \pm 0.10$ & $1.12 \pm 0.24$ & $0.48 \pm 0.08$ & $1.06 \pm 0.13$ \\
\hline Cortisol $(\mu M)$ & $0.51 \pm 0.11$ & $0.60 \pm 0.21$ & $0.53 \pm 0.08$ & $2.22 \pm 0.54$ & $0.49 \pm 0.24$ & $2.08 \pm 0.37$ \\
\hline $\mathrm{ACTH}(p M)$ & $20 \pm 3$ & $23 \pm 4$ & $24 \pm 4$ & $230 \pm 39$ & $26 \pm 4$ & $271 \pm 41$ \\
\hline$\beta$-Endorphin $(p M)$ & $28 \pm 3$ & $36 \pm 5$ & $25 \pm 3$ & $210 \pm 27$ & $31 \pm 4$ & $202 \pm 25$ \\
\hline Glucose $(m M)$ & $4.8 \pm 0.2$ & $5.0 \pm 0.3$ & $4.9 \pm 0.3$ & $7.4 \pm 0.6$ & $4.8 \pm 0.4$ & $7.2 \pm 0.4$ \\
\hline
\end{tabular}

Acoustic stress was begun at $0 \mathrm{~min}$ and $\mathrm{CRF}(0.5 \mathrm{nmol} / \mathrm{kg})$ or control (sterile water) were given cerebroventricularly at $0 \mathrm{~min}$. At $20 \mathrm{~min}$, there was a significant $(P<0.01)$ increase in plasma levels of all parameters measured in stressed and CRF-treated animals.

CRF significantly inhibited pancreatic volume secretion for $1 \mathrm{~h}$ (Fig. $1 B$ ). In addition, cerebral CRF $(1 \mathrm{nmol} / \mathrm{kg})$ inhibited total pancreatic protein secretion from $17.4 \pm 1.9$ to $8.1 \pm 0.9$ $\mathrm{mg} / \mathrm{h}(P<0.01)$ and total pancreatic bicarbonate secretion from $29.5 \pm 3.1$ to $10.7 \pm 0.9 \mu \mathrm{mol} / \mathrm{h}(P<0.01)$. In contrast, intravenous administration of CRF $(0.5 \mathrm{nmol} / \mathrm{kg}$ in dogs and $1.0 \mathrm{nmol} / \mathrm{kg}$ in rats) did not significantly alter CCK-induced gallbladder contraction or exocrine pancreatic secretion (data not shown).

Acoustic stress in dogs significantly reversed CCK-induced gallbladder contraction; the effect of stress was comparable to the effect of cerebral CRF $(0.1 \mathrm{nmol} / \mathrm{kg}$; Fig. $1 C)$. Restraint stress in rats and cerebral CRF $(1 \mathrm{nmol} / \mathrm{kg})$ inhibited pancreatic volume secretion similarly $(P<0.01$; Fig. $1 D)$. Restraint stress also inhibited total protein output by $52 \%$ and total bicarbonate output by $63 \%(P<0.01)$. Cerebral administration of $\alpha$-helical CRF-(9-41) 15 min before stress exposure or cerebral administration of CRF completely reversed their effects on gallbladder volume (Fig. $1 C$ ) and exocrine pancreatic secretion (Fig. $1 D$ ). These responses were measured $45 \mathrm{~min}$ after CRF (or control) administration or stress exposure. In CRF-treated animals and in stressed animals, the highest dose of $\alpha$-helical
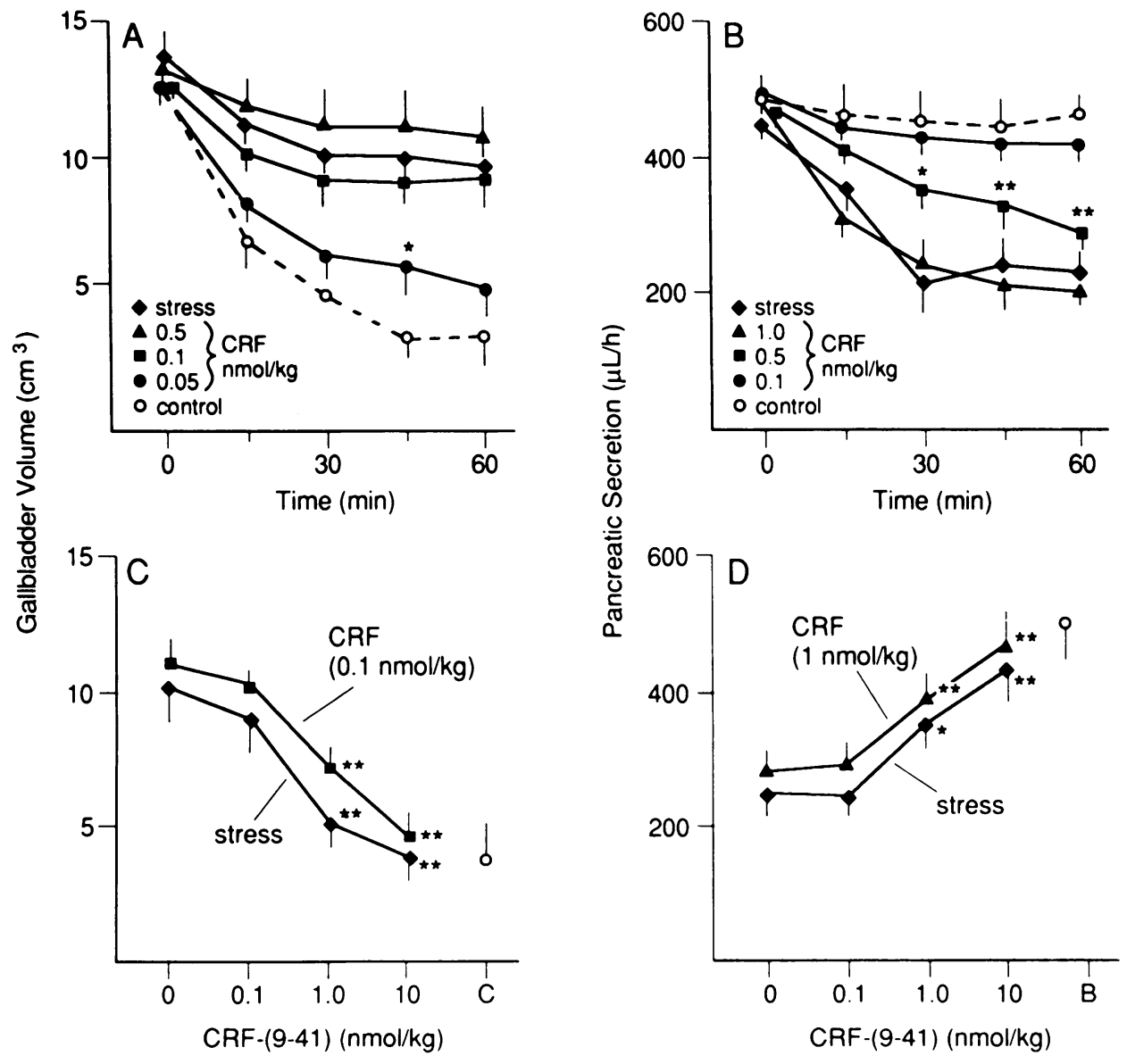

Figure 1. Effects of stress and cerebral CRF on canine gallbladder contraction and on rat pancreatic secretion. $(A)$ All groups received CCK ( $20 \mathrm{pmol} / \mathrm{kg}$ per $\mathrm{h})$ from time zero to $60 \mathrm{~min}$. Acoustic stress (0-60 $\mathrm{min}$ ) and cerebral CRF (at 0.1 and $0.5 \mathrm{nmol} / \mathrm{kg}$ ) given at time zero significantly $(P<0.01)$ reversed CCKinduced gallbladder contraction for $1 \mathrm{~h} .{ }^{*} P<0.05$ compared with control. $(B)$ Restraint stress $(0-60 \mathrm{~min})$ and cerebral CRF (at $1 \mathrm{nmol} / \mathrm{kg}$ ) given at time zero significantly $(P$ $<0.01$ ) inhibited pancreatic secretion for 1 h. ${ }^{*} P<0.05$ and ${ }^{* *} P$ $<0.01$ compared with control. $(C)$ All groups received CCK (20 pmol/ $\mathrm{kg}$ per $\mathrm{h}$ ), and gallbladder volumes were measured at $45 \mathrm{~min}$. The CRF antagonist, $\alpha$-helical CRF-(9-41) [CRF-(9-41)], given $15 \mathrm{~min}$ before stress exposure or cerebral CRF, dose-dependently reversed stressand CRF-induced gallbladder relaxation. $C$ on abscissa denotes animals treated with CCK alone. ${ }^{*} P<0.05$ and ${ }^{* *} P<0.01$ compared with zero dose (sterile water). $(D)$ Cerebral CRF-(9-41) given $15 \mathrm{~min}$ before stress exposure or cerebral CRF dose-dependently reversed stressand CRF-induced inhibition of pancreatic secretion. $B$ on abscissa denotes basal secretion. ${ }^{*} P<0.05$ and ${ }^{* *} P<0.01$ compared with zero dose. 
CRF-(9-41) $(10 \mathrm{nmol} / \mathrm{kg})$ produced responses that were similar to those observed with CCK alone (Fig. $1 C$ ) and that were similar to basal pancreatic secretion (Fig. $1 D$ ).

Stimulated gallbladder contraction and pancreatic secretion. To examine the effects of stress and CRF on endogenously induced gallbladder contraction, a balanced, blenderized mixed meal was administered intragastrically. Both acoustic stress and cerebral CRF $(0.5 \mathrm{nmol} / \mathrm{kg})$ reversed meal-induced gallbladder contraction (Fig. $2 \mathrm{~A}$ ). At the 30-, 45-, and 60-min intervals, gallbladder volumes in stressed and in CRF-treated animals were nearly identical to basal volumes. To simulate postprandial exocrine pancreatic secretion, a combined infusion of CCK and secretin was administered intravenously. Both restraint stress and CRF abolished the protein and bicarbonate responses (Fig. 2, $B$ and $C$ ) as well as volume secretion (not shown). In control experiments, the stimulated responses were protein, $34.3 \pm 0.4 \mathrm{mg} / \mathrm{h}$; bicarbonate, $40.1 \pm 0.5 \mu \mathrm{mol} / \mathrm{h}$; and volume, $985 \pm 57 \mu \mathrm{l} / \mathrm{h}$. In stressed animals, the respective responses were $20.4 \pm 1.5 \mathrm{mg} / \mathrm{h}, 29.4 \pm 2.4 \mu \mathrm{mol} / \mathrm{h}$, and $595 \pm 42$ $\mu \mathrm{l} / \mathrm{h}(P<0.01$ compared with the appropriate control). In CRF-treated animals, the respective responses were 20.5 \pm 0.9 $\mathrm{mg} / \mathrm{h}, 28.5 \pm 2.9 \mu \mathrm{mol} / \mathrm{h}$, and $575 \pm 44 \mu \mathrm{l} / \mathrm{h}(P<0.01$ compared with the appropriate control).
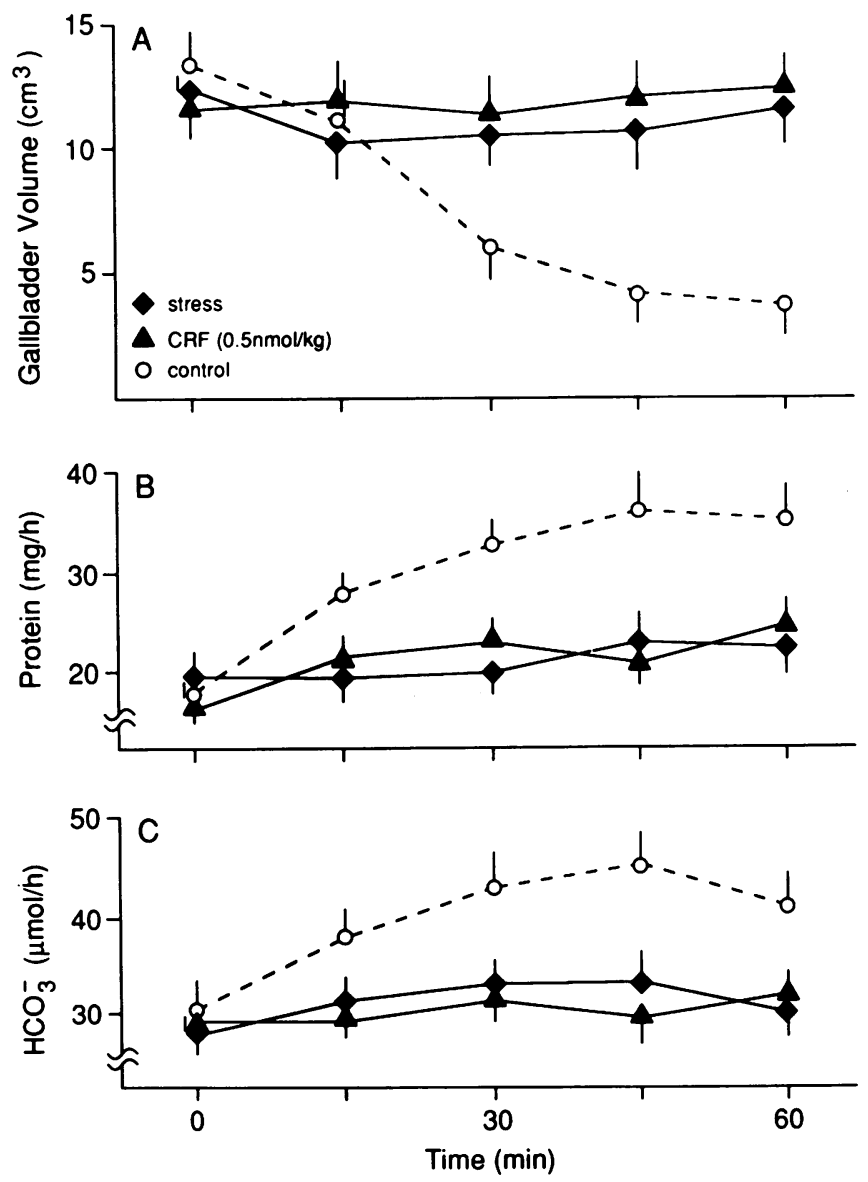

Figure 2. Effects of stress and cerebral CRF on meal-stimulated gallbladder contraction $(A)$ and $\mathrm{CCK} /$ secretin-stimulated pancreatic secretions $(B$ and $C)$. The mixed meal $(240 \mathrm{ml})$ was administered intragastrically at time zero. CCK and secretin (10 pmol/kg per h each) were given intravenously (0-60 min). Both stress and CRF significantly $(P<0.01)$ reversed the effects of the mixed meal $(A, 30-60$ $\mathrm{min}$ ) and the effects of $C \mathrm{CK} / \mathrm{secretin}(B$ and $C, 15-60 \mathrm{~min}$ ).
Neurohumoral pathways. Fig. 3 depicts the effects of ganglionic blockade with chlorisondamine, noradrenergic blockade with bretylium, and truncal vagotomy on gallbladder volume (Fig. $3 \mathrm{~A}$ ) and pancreatic secretion (Fig. $3 \mathrm{~B}$ ) in the resting state, during stress, and after cerebral administration of CRF (0.1 $\mathrm{nmol} / \mathrm{kg}$ in dogs and $1.0 \mathrm{nmol} / \mathrm{kg}$ in rats). Neither stress nor cerebral administration of $\mathrm{CRF}$ altered resting (fasting) gallbladder volume (Fig. $3 A)$, but chlorisondamine $(P>0.05)$ and vagotomy $(P<0.05)$ diminished basal pancreatic secretion, whereas bretylium did not (Fig. $3 B$ ). In dogs, both chlorisondamine and bretylium, but not vagotomy, prevented the reversal of CCK-induced gallbladder contraction produced by CRF and stress that was observed in animals treated with $\mathrm{NaCl}$ (Fig. $3 \mathrm{~A}$ ). Similarly, in rats, chlorisondamine and bretylium, but not vagotomy, abolished the inhibitory actions of CRF and stress on exocrine pancreatic secretion (Fig. $3 B$ ). Hypophysectomy in rats, adrenalectomy, propranolol, and naloxone in rats and dogs, as well as exogenous infusion of ACTH or $\beta$-endorphin $(100 \mathrm{pmol} / \mathrm{kg}$ per $\mathrm{h}$ each) administered to rats and dogs, did not significantly alter the effects of cerebral CRF and stress on gallbladder volume and pancreatic secretion during the basal state (Tables II and III).

Noradrenergic pathways. To determine whether norepinephrine is the common peripheral neurotransmitter mediating the effects of stress and CRF on gallbladder motility and exocrine pancreatic secretion, this catecholamine was given exogenously and the biological responses were measured. Table IV shows that norepinephrine $(100 \mathrm{nmol} / \mathrm{kg}$ per $\mathrm{h})$ produced plasma levels that were similar to those previously observed in response to CRF and restraint stress in rats (4) and to those observed in response to CRF in dogs (21) and in response to acoustic stress (Table I). This dose of norepinephrine also produced a reversal of CCK-induced gallbladder contraction (Fig. $4 \mathrm{~A}$ ) and inhibition of exocrine pancreatic secretion (Fig. $4 B$ ). These responses were similar to those produced by stress and cerebral CRF $(0.1 \mathrm{nmol} / \mathrm{kg}$ in dogs and $1.0 \mathrm{nmol} / \mathrm{kg}$ in rats). Increasing doses of the $\alpha$-adrenergic receptor antagonist phentolamine significantly reversed the effects of cerebral CRF, stress, and exogenous norepinephrine on gallbladder volume and pancreatic secretion (Fig. 4). At the highest dose of phentolamine $(10 \mu \mathrm{mol} / \mathrm{kg}$ per h), gallbladder volume and pancreatic secretion in all treatment groups were similar compared with gallbladder volume in dogs treated with CCK alone and in rats at basal, respectively. The difference between pancreatic secretion in stressed animals treated with phentolamine (10 $\mu \mathrm{mol} / \mathrm{kg}$ per $\mathrm{h}$ ) and basal secretion was not significant (Fig. $4 B)$.

\section{Discussion}

Gallbladder contraction and exocrine pancreatic secretion subserve important digestive functions facilitating the coordinated postprandial digestion and subsequent absorption of fat, protein, and carbohydrates (1). Both the gallbladder and the exocrine pancreas enjoy a rich supply of noradrenergic nerve fibers, but their physiological (or pathophysiological) importance for gut function has not been defined $(6,7)$. Using two new animal models, we have found that, during stress, activation of noradrenergic outflow to the gut mediated by cerebral CRF produces inhibition of canine gallbladder contraction and murine exocrine pancreatic secretion. 

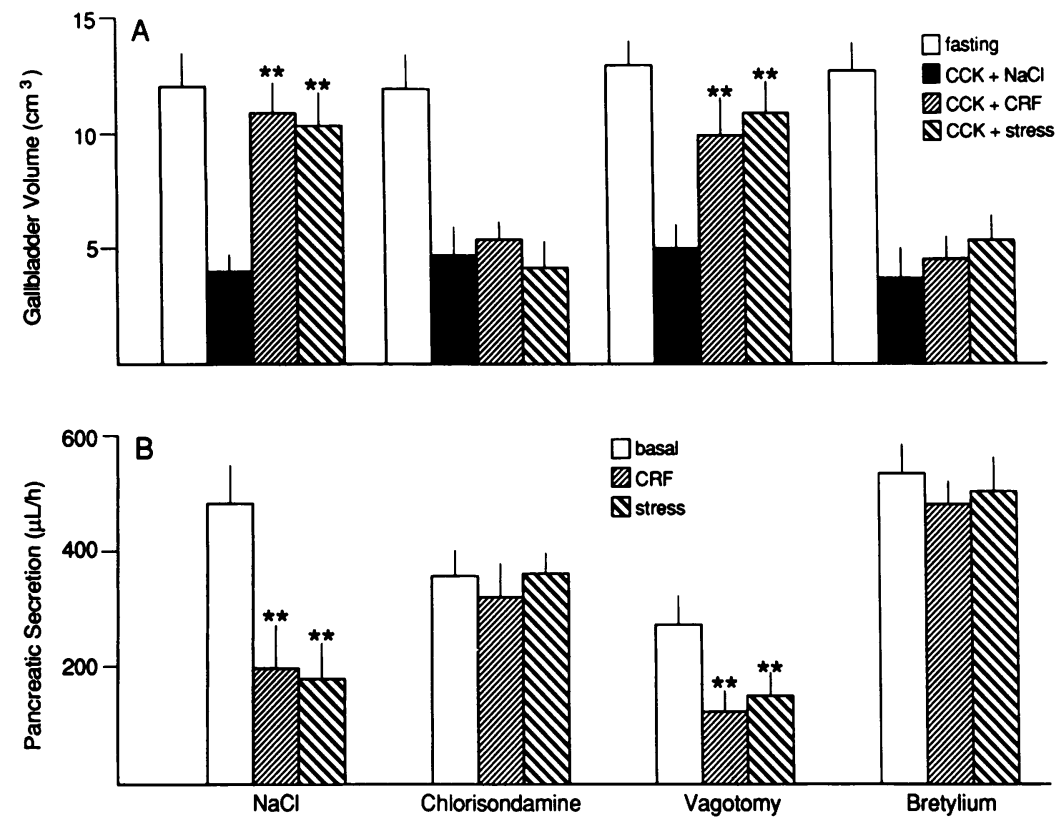

Figure 3. Neuronal pathways mediating stress- and CRF-induced gallbladder relaxation and inhibition of exocrine pancreatic secretion. (A) Gallbladder volume was measured $45 \mathrm{~min}$ after administration of CCK, cerebral CRF $(0.1 \mathrm{nmol} / \mathrm{kg})$, and acoustic stress. $(B)$ Pancreatic secretion was measured in response to cerebral CRF ( $1 \mathrm{nmol} / \mathrm{kg})$ and restraint stress. Ganglionic blockade with chlorisondamine $(1 \mathrm{mg} / \mathrm{kg})$, truncal vagotomy, and noradrenergic blockade with bretylium $(10 \mathrm{mg} / \mathrm{kg}$ per $\mathrm{h})$ were performed. ${ }^{* *} P$ $<0.01$ compared with $\mathrm{CCK}+\mathrm{NaCl}(A)$ or with basal $(B)$.

Cerebral administration of CRF dose-dependently inhibited CCK-induced gallbladder contraction in awake dogs and basal pancreatic secretions (volume, protein, and bicarbonate) in awake, freely moving rats. CRF also inhibited gallbladder contraction produced by a physiological stimulus, a balanced mixed meal, and CCK/secretin-stimulated exocrine pancreatic secretions. In contrast, a high dose of CRF administered intravenously did not alter biliary and pancreatic functions, suggesting that CRF exerts its biological actions within the central nervous system at a yet-undefined site.

We have previously shown that restraint stress elicits characteristic neuroendocrine stress responses in rats (4). We have now demonstrated that acoustic stress increases plasma concentrations of norepinephrine, epinephrine, glucose, cortisol, $\mathrm{ACTH}$, and $\beta$-endorphin. These responses are quantitatively similar to those observed after exogenous administration of CRF $(4,21)$. A similar type of acoustic stress has been demonstrated to inhibit canine gastric motor function $(26,27)$. In a manner comparable to the higher doses of exogenously administered CRF, acoustic stress inhibits CCK- and meal-induced canine gallbladder contraction and restraint stress inhibits basal exocrine pancreatic secretion in rats. The responses elicited by both stress and exogenous CRF were inhibited by cerebral administration of the CRF receptor antagonist, $\alpha$-helical CRF(9-41) (23), in a dose-related fashion. These results indicate that CRF is released in response to different stressors in distinct species, exerting its central nervous system effects on gut function via specific CRF receptors. Of interest, the dose of the antagonist required to abolish the effects of CRF was 10 times less in rats than in dogs. This may be secondary to differences in peptide distribution or tissue penetration or to decreased affinity of the canine CRF receptor for $\alpha$-helical CRF-(9-41).

Previously validated surgical and pharmacological approaches were utilized to delineate the neurohumoral efferents mediating the effects of stress and CRF. Ganglionic and noradrenergic blockade and truncal vagotomy did not significantly alter gallbladder volume, indicating that autonomic efferents do not exert a tonic control over gallbladder volume at rest (6). In contrast, ganglionic blockade with chlorisondamine slightly (but insignificantly) and vagotomy significantly diminished resting pancreatic secretion, confirming that vagal efferents control resting exocrine pancreatic secretion (7). However, the effects of acoustic stress in dogs and the effects of restraint stress in rats on gallbladder volume and on pancreatic secretion, respectively, were completely abolished by ganglionic and noradrenergic blockade. In contrast, vagotomy, adrenalectomy, and

Table II. Role of Neuroendocrine Pathways Mediating Stress- and CRF-induced Gallbladder Relaxation

\begin{tabular}{|c|c|c|c|c|c|c|}
\hline & \multicolumn{2}{|c|}{ Control } & \multicolumn{2}{|c|}{ Stress } & \multicolumn{2}{|c|}{ CRF } \\
\hline & $0 \min$ & $30 \mathrm{~min}$ & $0 \min$ & $30 \mathrm{~min}$ & $0 \min$ & $30 \mathrm{~min}$ \\
\hline & \multicolumn{6}{|c|}{$\mathrm{cm}^{3}$} \\
\hline Adrenalectomy & $12.8 \pm 1.9$ & $5.0 \pm 0.9$ & $12.1 \pm 0.9$ & $11.4 \pm 0.8$ & $10.4 \pm 0.9$ & $9.9 \pm 1.6$ \\
\hline Propranolol & $11.1 \pm 1.4$ & $5.1 \pm 1.1$ & $10.4 \pm 1.3$ & $10.4 \pm 1.8$ & $11.4 \pm 1.4$ & $9.7 \pm 0.9$ \\
\hline Naloxone & $12.9 \pm 1.4$ & $6.2 \pm 1.4$ & $11.3 \pm 2.0$ & $10.5 \pm 1.8$ & $10.7 \pm 1.9$ & $9.6 \pm 1.1$ \\
\hline$\beta$-Endorphin & $13.1 \pm 1.5$ & $5.9 \pm 1.3$ & $12.3 \pm 0.8$ & $10.4 \pm 0.8$ & $13.0 \pm 1.8$ & $9.9 \pm 1.4$ \\
\hline ACTH & $10.7 \pm 2.1$ & $4.4 \pm 0.8$ & $13.2 \pm 1.7$ & $11.2 \pm 0.9$ & $11.3 \pm 1.1$ & $9.4 \pm 0.8$ \\
\hline
\end{tabular}

In each treatment group, acoustic stress and cerebral CRF $(0.5 \mathrm{nmol} / \mathrm{kg})$ reversed CCK-induced gallbladder contraction compared with control experiments. Agents were administered as described in Methods. 
Table III. Role of Neuroendocrine Pathways Mediating Stress- and CRF-induced Inhibition of Pancreatic Secretion

\begin{tabular}{|c|c|c|c|c|c|c|}
\hline & \multicolumn{2}{|c|}{ Control } & \multicolumn{2}{|c|}{ Stress } & \multicolumn{2}{|c|}{ CRF } \\
\hline & $0 \mathrm{~min}$ & $30 \mathrm{~min}$ & $0 \min$ & $30 \mathrm{~min}$ & $0 \min$ & $30 \mathrm{~min}$ \\
\hline & \multicolumn{6}{|c|}{$\mu l / h$} \\
\hline Hypophysectomy & $440 \pm 49$ & $420 \pm 39$ & $470 \pm 41$ & $220 \pm 27$ & $460 \pm 36$ & $231 \pm 40$ \\
\hline Adrenalectomy & $490 \pm 56$ & $459 \pm 46$ & $474 \pm 49$ & $279 \pm 43$ & $474 \pm 39$ & $230 \pm 47$ \\
\hline Propranolol & $510 \pm 67$ & $480 \pm 57$ & $539 \pm 86$ & $241 \pm 68$ & $510 \pm 47$ & $276 \pm 56$ \\
\hline Naloxone & $495 \pm 45$ & $439 \pm 44$ & $522 \pm 37$ & $260 \pm 34$ & $513 \pm 56$ & $269 \pm 37$ \\
\hline$\beta$-Endorphin & $420 \pm 39$ & $403 \pm 42$ & $408 \pm 44$ & $243 \pm 31$ & $428 \pm 47$ & $210 \pm 33$ \\
\hline ACTH & $481 \pm 56$ & $473 \pm 71$ & $505 \pm 49$ & $257 \pm 56$ & $496 \pm 39$ & $260 \pm 22$ \\
\hline
\end{tabular}

In each treatment group, restraint stress and cerebral CRF $(1 \mathrm{nmol} / \mathrm{kg})$ significantly $(P<0.01)$ inhibited pancreatic volume secretion. Agents were administered as described in Methods.

hypophysectomy (in rats) did not alter the effects of stress and CRF on biliary and pancreatic function. These results indicate that both stress and CRF exert their effects on the gallbladder and the exocrine pancreas via sympathetic noradrenergic efferents. This conclusion is further strengthened by the lack of effect of adrenalectomy, $\beta$-adrenergic blockade, naloxone, or exogenous administration of ACTH and $\beta$-endorphin. These results concur with previous observations that indicate that CRF exerts its effects on gastrointestinal secretory and motor function by modulating autonomic nervous system activity (13-17, 21, 22). In contrast, stress-induced stimulation of murine duodenal bicarbonate secretion is mediated by endogenous CRF and subsequent release of $\beta$-endorphin (18), but this pathway appears to be an exception.

Cutting the splanchnic nerves increases vagally stimulated pancreatic secretion (28), whereas splanchnic nerve stimulation inhibits pancreatic secretion (29). Catecholamines have been implicated to mediate these responses either directly or indirectly by decreasing blood flow to the pancreas (30). Whereas $\beta$-adrenergic agonists have been reported either to have no effect or to cause inhibition of stimulated secretion, $\alpha$-adrenergic agonists clearly cause inhibition in vivo (31 and references therein). Similarly, stimulation of splanchnic nerves inhibits the contractile effects of CCK on feline gallbladder (6), and norepinephrine relaxes guinea pig and cat gallbladder in vivo and in vitro (6 and references therein; also 30, 32-34). In addition to these pharmacological observations, our results indicate that endogenous stimulation of sympathetic noradrener- gic outflow by two different stressors inhibits murine pancreatic and canine biliary motor function.

It was of interest that endogenously released CRF appeared to exert its actions on two different peripheral organ functions in distinct species by a common noradrenergic pathway. To further investigate the importance of noradrenergic control over biliary and pancreatic function during stress, norepinephrine was administered at a dose that produced plasma concentrations similar to those observed in response to CRF and stress. Of note, intravenous administration of norepinephrine produced reversal of CCK-induced gallbladder contraction and inhibition of pancreatic secretion $(29,32,34)$ that were similar to those observed in response to stress or CRF. Furthermore, the effects of all three stimuli-exogenous CRF, stress, and norepinephrine-were dose-dependently abolished by peripheral administration of the $\alpha$-adrenergic receptor antagonist phentolamine but not by propranolol. These results indicate that $\alpha$-adrenergic receptors are likely to be the final target for norepinephrine released in response to stress and exogenously administered CRF. These findings are in accord with previous observations that suggest that CRF and stress exert their central nervous system actions on the upper gastrointestinal tract via sympathetic noradrenergic efferents $(5,15-17,21,22,35)$.

Our results differ from previous studies in anesthetized cats, which indicated that the relaxing effect of norepinephrine on the gallbladder was mediated by $\beta$-adrenergic receptors (33). In this investigation, removal of the primary $\beta$-adrenergic agonist epinephrine by adrenalectomy and $\beta$-adrenergic blockade

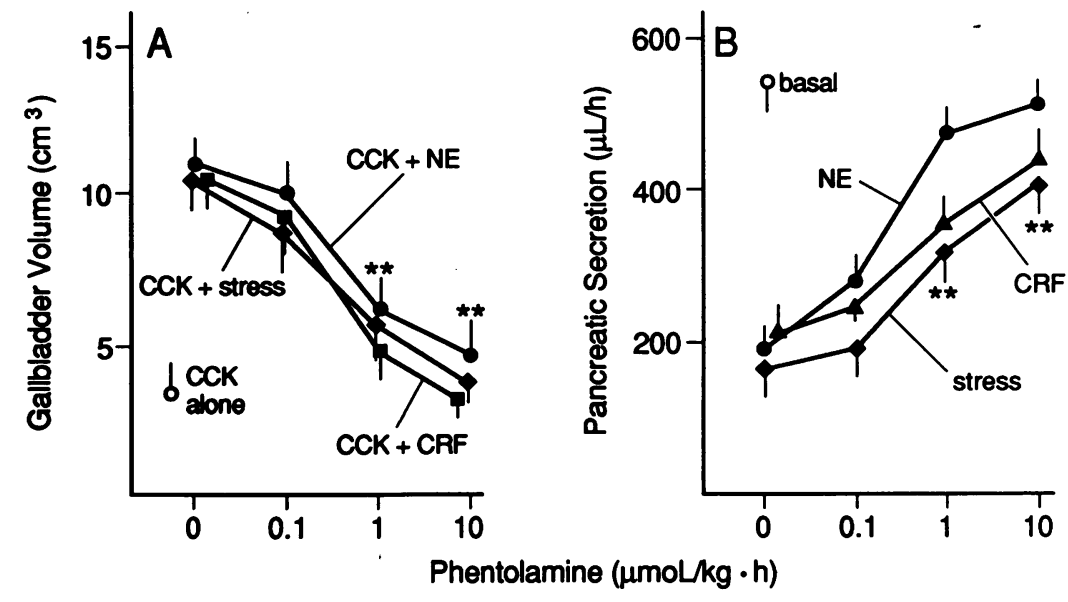

Figure 4. Reversal of CRF-, stress-, and norepinephrine $(N E)$-induced gallbladder relaxation and inhibition of pancreatic secretion by the $\alpha$-adrenergic receptor antagonist phentolamine. $(A)$ Gallbladder volume was measured at $45 \mathrm{~min}$ after administration of CCK, cerebral CRF $(0.1 \mathrm{nmol} / \mathrm{kg})$, intravenous NE $(100 \mathrm{nmol} / \mathrm{kg}$ per $\mathrm{h})$, and acoustic stress. (B) Pancreatic secretion was measured in response to cerebral CRF (1 nmol $/ \mathrm{kg})$, intravenous NE (100 nmol $/ \mathrm{kg}$ per $\mathrm{h}$ ), and restraint stress. In both species, phentolamine (at 1 and $10 \mu \mathrm{mol} / \mathrm{kg}$ per $\mathrm{h}$ ) significantly $\left({ }^{* *} P<0.01\right)$ reversed the biological actions produced by stress, $\mathrm{CRF}$, and NE. 
Table IV. Plasma Concentrations of Norepinephrine

\begin{tabular}{lcccc}
\hline \multicolumn{5}{c}{ Norepinephrine } \\
\cline { 2 - 5 } & $0 \mathrm{~min}$ & $20 \mathrm{~min}$ & $40 \mathrm{~min}$ & $60 \mathrm{~min}$ \\
\hline & \multicolumn{4}{c}{$n M$} \\
Rats & $0.78 \pm 0.15$ & $1.90 \pm 0.31$ & $2.47 \pm 0.48$ & $2.22 \pm 0.57$ \\
Dogs & $1.10 \pm 0.27$ & $2.89 \pm 0.41$ & $3.22 \pm 0.65$ & $3.02 \pm 0.52$
\end{tabular}

Norepinephrine ( $100 \mathrm{nmol} / \mathrm{kg}$ per $\mathrm{h})$ was infused intravenously from 0 to $60 \mathrm{~min}$. Plasma levels were significantly $(P<0.01)$ increased (20-60 min) but not significantly different from those after acoustic stress and CRF in dogs (Table I) or after restraint stress and CRF in rats (reference 4).

did not alter CRF- and stress-induced inhibition of gallbladder contraction in awake, nonanesthetized dogs. Furthermore, propranolol did not inhibit the relaxing effects of norepinephrine on CCK-induced gallbladder contraction (unpublished observations). Finally, in this study, a "physiologic" dose of norepinephrine was used that mimicked plasma concentrations that were observed in response to stress. Species differences and study design (bolus vs. continuous infusion of agonist and antagonist, as well as the state of anesthesia) may account for these diverse observations. The specific site of action for norepinephrine to induce $\alpha$-receptor-mediated canine gallbladder contraction remains to be defined in vitro.

We conclude that stress, exogenous CRF, and norepinephrine inhibit canine gallbladder contraction and murine exocrine pancreatic secretion. Different stressors (acoustic and restraint stress) in distinct species release CRF that acts on specific CRF receptors within the brain. Release of norepinephrine appears to be the final common pathway producing inhibition of biliary and pancreatic function during stress mediated by endogenous CRF.

\section{Acknowledgments}

The authors thank K. Feutlinske and E. Friemel for technical assistance and J. E. Rivier for generous supply of peptides.

This work was supported by the Deutsche Forschungsgemeinschaft, Hamburgische Wissenschaftliche Stiftung, and the National Institutes of Health (NIH). H. J. Lenz is recipient of an NIH Clinical Investigator Award.

\section{References}

1. Johnson, L. R. 1987. Physiology of the Gastrointestinal Tract. Raven Press, New York. 1780 pp.

2. Hölzl, R., and W. E. Whitehead. 1983. Psychophysiology of the Gastrointestinal Tract. Plenum Press, New York. 360 pp.

3. Williams, C. L., J. M. Peterson, R. G. Villar, and T. F. Burks. 1987. Corticotropin-releasing factor directly mediates colonic responses to stress. $\mathrm{Am}$. $J$. Physiol. 253:G582-G586.

4. Lenz, H. J., A. Raedler, H. Greten, W. W. Vale, and J. E. Rivier. 1988. Stress-induced gastrointestinal secretory and motor responses in rats are mediated by endogenous corticotropin-releasing factor. Gastroenterology. 95:15101517.

5. Lenz, H. J. 1989. Neurohumoral pathways mediating stress-induced changes in rat gastrointestinal transit. Gastroenterology. 97:216-218.

6. Ryan, J. P. 1987. Motility of the gallbladder and biliary tree. In Physiology of the Gastrointestinal Tract. L. R. Johnson, editor. Raven Press, New York. 695-722.

7. Singer, M. V. 1986. Neurohumoral control of pancreatic enzyme secretion in animals. In The Exocrine Pancreas: Biology, Pathobiology and Diseases V. L. W. Go, J. D. Gardner, F. P. Brooks, E. Lebenthal, E. P. DiMagno, and G. A. Scheele, editors. Raven Press, New York. 315-332.

8. Porte, D., Jr. 1973. Neural regulation of insulin secretion in the dog. J. Clin. Invest. 52:210-214.
9. Ahren, B., R. C. Veith, and G. J. Taborsky, Jr. 1987. Sympathetic nerve stimulation vs. pancreatic norepinephrine infusion in the dog. 1 . Effects on basal insulin and glucagon release. Endocrinology. 121:323-331.

10. Marliss, E. B., L. Girardier, J. Seydoux, C. B. Wollheim, Y. Kanazawa, L. Orci, A. E. Renold, and D. Porte, Jr. 1973. Glucagon secretion induced by pancreatic nerve stimulation in the dog. J. Clin. Invest. 52:1246-1249.

11. Havel, P. J., R. C. Veith, B. E. Dunning, and J. Taborsky, Jr. 1990. Pancreatic noradrenergic nerves are activated by neuroglucopenia but not by hypotension or hypoxia in the dog. Evidence for stress-specific and regionally selective activation of the sympathetic nervous system. J. Clin. Invest. 82:15381545 .

12. Rivier, J., J. Spiess, and W. Vale. 1983. Characterization of rat hypothalamic corticotropin-releasing factor. Proc. Natl. Acad. Sci. USA. 80:4851-4855.

13. Tache, Y., Y. Goto, W. Gunion, W. Vale, J. Rivier, and M. Brown. 1983. Inhibition of gastric acid secretion in rats by intracerebral injection of corticotropin-releasing factor. Science (Wash. DC). 222:935-937.

14. Tache, Y., M. Maeda-Hagiwara, and C. M. Turkelson. 1987. Central nervous system action of corticotropin-releasing factor to inhibit gastric emptying in rats. Am. J. Physiol. 253:G241-G245.

15. Lenz, H. J., S. E. Hester, and M. R. Brown. 1985. Corticotropin-releasing factor: mechanisms to inhibit gastric acid secretion in conscious dogs. J. Clin. Invest. 75:889-895.

16. Lenz, H. J., M. Burlage, A. Raedler, and H. Greten. 1988. Central nervous system effects of corticotropin-releasing factor on gastrointestinal transit in the rat. Gastroenterology. 94:598-602.

17. Drüge, G., A. Raedler, H. Greten, and H. J. Lenz. 1989. Pathways mediating CRF-induced inhibition of gastric acid secretion in rats. Am. J. Physiol. 256:G214-G219.

18. Lenz, H. J. 1989. Regulation of duodenal bicarbonate secretion during stress by corticotropin-releasing factor and $\beta$-endorphin. Proc. Natl. Acad. Sci. USA. 86:1417-1420.

19. Gunion, M. W., G. L. Kauffman, Jr., and Y. Tache. 1990. Intrahypothalamic corticotropin-releasing factor elevates gastric bicarbonate and inhibits stress ulcers in rats. Am. J. Physiol 258:G152-G157.

20. Brown, M. R., L. A. Fisher, J. Spiess, C. Rivier, J. Rivier, and W. Vale. 1982. Corticotropin-releasing factor: action on the sympathetic nervous system and metabolism. Endocrinology. 111:928-931.

21. Lenz, H. J., A. Raedler, H. Greten, and M. R. Brown. 1987. Corticotropin-releasing factor initiates biological actions within the brain that are observed in response to stress. Am. J. Physiol. 252:R34-R39.

22. Lenz, H. J. 1989. Neuroendocrine regulation of canine gastric secretion, emptying and blood flow. J. Neuroendocrinol. 1:163-167.

23. Rivier, J., C. Rivier, and W. Vale. 1984. Synthetic competitive antagonists of corticotropin-releasing factor: effect on ACTH secretion in the rat. Science (Wash. DC). 224:889-891.

24. Everson, G. T., D. Z. Braverman, M. L. Johnson, and F. Kern, Jr. 1980. A critical evaluation of real-time ultrasonography for the study of gallbladder volume and contraction. Gastroenterology. 79:40-46.

25. Lowry, O. H., N. J. Rosebrough, A. L. Farr, and R. J. Randall. 1951. Protein measurement with the Folin phenol reagent. J. Biol. Chem. 193:265-275.

26. Gue, M., and L. Bueno. 1986. Diazepam and muscimol blockade of the gastrointestinal motor disturbances induced by acoustic stress in dogs. Eur. $J$. Pharmacol. 131:123-127.

27. Gue, M., J. Fioramonti, J. Frexinos, M. Alvinerie, and L. Bueno. 1987. Influence of acoustic stress by noise on gastrointestinal motility in dogs. Dig. Dis. Sci. 32:1411-1417.

28. Holst, J. J., S. Khnuhtsen, S. L. Jensen, O. V. Nielsen, and S. S. Poulsen. 1984. Paracrine somatostatin and GRP-nerves in the control of antral gastrin release. Dig. Dis. Sci. 29(Suppl.):37S.

29. Barlow, T. E., J. R. Greenwell, A. A. Harper, and T. Scratcherd. 1971. The effect of adrenaline and noradrenaline on blood flow, electrical conductance and external secretion of the pancreas. J. Physiol. (Lond.). 217:665-678.

30. Demol, P., and H. Sarles. 1980. Action of catecholamines on the exocrine pancreatic secretion of conscious rats. Arch. Int. Pharmacodyn. Ther. 243:149163.

31. Holst, J. J. 1986. Neural regulation of pancreatic exocrine function. In The Exocrine Pancreas: Biology, Pathobiology, and Diseases. V. L. W. Go, J. D. Gardner, F. P. Brooks, E. Lebenthal, E. P. DiMagno, and G. A. Scheele, editors. Raven Press, New York. 287-300.

32. Palin, B., and S. Skoglund. 1964. Neural and humoral control of gallbladder emptying mechanism in the cat. Acta Physiol. Scand. 60:358-362.

33. Persson, C. G. A. 1973. Dual effects on the sphincter of Oddi and gallbladder induced by stimulation of the right splanchnic nerves. Acta Physiol. Scand. 87:334-343.

34. Bertaccini, G., G. DeCaro, R. Endean, V. Erspamer, and M. Impicciatore. 1986. The action of caerulein on the smooth muscle of the gastrointestinal tract and the gallbladder. Br. J. Pharmacol. 34:291-310.

35. Lenz, H. J., and G. Drüge. 1990. Neurohumoral pathways mediating stress-induced inhibition of gastric acid secretion in rats. Gastroenterology. 98:1490-1492. 